\title{
DESCONTAMINAÇÃO INADEQUADA DOS ENDOSCÓPIOS E ACESSÓRIOS. Essa é a realidade brasileira?
}

\author{
DESCRITORES - Contaminação de equipamentos. Desinfecção. Endoscópios.
}

O risco de contaminação com a utilização de aparelhos endoscópicos e acessórios para diagnóstico e, em especial, para procedimentos terapêuticos é amplamente conhecido ${ }^{(1,6)}$. Os meios para conseguir evitar ou pelo menos diminuir o risco, são atualmente bem definidos $^{(1,9,11)}$. Por que então, os endoscopistas, mesmo sabendo de todos esses conceitos e conhecimentos não estão convencidos da sua relevância e principalmente da sua aplicação?

Isto realmente acontece, sobretudo ao se observar as poucas e corajosas publicações sobre o assunto ${ }^{(2,10)}$, ainda demonstrando que a limpeza inapropriada e o curto período de tempo de desinfecção são os maiores fatores associados à presença de microrganismos em endoscópios $^{(2,10)}$.

A resposta é multifatorial e certamente, não totalmente transparente. Observa-se isto quando se constata que a conclusão de COSTA et al.(2), em 1997, não difere desta que MACHADO et al. ${ }^{(5)}$ publicam nesta edição dos ARQUIVOS de GASTROENTEROLOGIA. O resultado desta pesquisa bem conduzida demonstrou quase $50 \%$ de positividade para bactérias vegetativas. Ora, o nível de resistência dos microorganismos aos procedimentos de desinfecção é bem conhecido, sendo que as bactérias vegetativas e mesmo as gram-negativas, assim como as leveduras e vírus (HIV, HBV e HCV) são suscetíveis a uma desinfecção de baixo nível (fricção mecânica com água e detergente) $)^{(9,11)}$.

MORRIS et al. ${ }^{(6)}$, em revisão recente, revelaram que o risco da transmissão viral por equipamentos e acessórios descontaminados de forma inadequada é conhecida e baixa. Esses autores revisaram a literatura na tentativa de determinar episódios de transmissão viral nestas circunstâncias. No total, 31 artigos foram incluídos e em nenhum deles identificou-se a transmissão do vírus da imunodeficiência adquirida (HIV). Os artigos incluídos na maioria das vezes são relatos de casos e foram escritos antes dos padrões de desinfecção detalhados hoje em $\operatorname{dia}^{(1,11)}$. Os resultados também sugerem que a transmissão das hepatites $\mathrm{B}$ e C é baixa durante a endoscopia, mesmo com a descontaminação inadequada dos equipamentos e acessórios, já comprovada amplamente pela literatura ${ }^{(2,4)}$. Apesar disso, todos os cuidados devem ser adotados para diminuir, ainda mais, esse risco de contaminação ${ }^{(10)}$.

Deve-se lembrar de conceito importante: a desinfecção e mesmo a esterilização, são processos relativos, isto é, têm a capacidade de redução microbiana da ordem de 1 milhão de unidades formadoras de colônias de bactéria por $\mathrm{mL}$ ou partículas virais. Isto significa, na prática, que se um instrumento não estiver adequadamente limpo, com restos de materiais (secreção purulenta $\rightarrow$ conteúdo de bactéria $=1$ bilhão; fezes $\rightarrow$ conteúdo $=1$ bilhão), ao final da desinfecção, poderemos ter uma quantidade de microrganismos $=1000$, que é biologicamente incompatível, quer dizer, há risco de se adquirir infecção a partir desta quantidade de bactéria ${ }^{(1,11)}$.

Se esse instrumento for submetido a limpeza rigorosa, terá 10 de cultura de bactérias ou vírus e ao final da desinfecção, irá a 0,00001 (esta é a redução esperada), que é conteúdo biologicamente aceitável, para equipamentos considerados semi-críticos ${ }^{(1,11)}$. Ou seja, podemos entender que a limpeza "escrupulosa" dos endoscópios, com água corrente, escova e detergente, retirando qualquer resíduo orgânico, incluindo seus canais internos e válvulas, é essencial, pouco dispendiosa e fácil. Tendo a mesma importância o sistema de secagem, com a retirada da umidade ${ }^{(7,10)}$

A próxima etapa é conhecer qual o tempo adequado de imersão dos aparelhos para desinfecção química, manual ou automaticamente. As organizações profissionais norte-americanas recomendam 20 minutos e as européias 10 . Pode-se considerar que os 20 minutos são para fins de normatização, com margem de segurança, por causa de algumas variáveis (limpeza correta, secagem adequada e cronometragem fiel). Na prática, se tiver essas variáveis sob controle, é possível obter uma desinfecção adequada com a ação do glutaraldeído $2 \%$ por 10 minutos. Necessário enfatizar que os acessórios são considerados críticos, ou seja, precisam de esterilização, por meio químico ou físico ${ }^{(1,7,8,11)}$. 
Têm-se que considerar que o nosso meio tem poder aquisitivo incomparavelmente menor do que em países como EUA, Inglaterra, Alemanha e França, onde a maioria dos acessórios são descartáveis ${ }^{(3)}$ e onde os serviços possuem um número de aparelhos que permite 30 minutos de desinfecção entre um exame e outro, sem alterar a produtividade do serviço $^{(11)}$. Porém, não é muito diferente de vários outros países, que encontram as mesmas dificuldades e para os quais foram publicadas recomendações especiais pela Organização Mundial de Gastroenterologia, admitindo adaptações ${ }^{(11)}$.
No Brasil, conta-se com publicações bastante úteis, detalhadas e confiáveis de orientação com relação ao processamento dos aparelhos e acessórios e é inaceitável que elas sejam ignoradas ${ }^{(1,9)}$.

Que este alerta sensibilize os colegas endoscopistas e suas equipes, quanto às suas responsabilidades médicas e civis.

Eloá Marussi MORSOLETTO ${ }^{1}$ Heda Maria dos Santos AMARANTE ${ }^{2}$ José Celso ARDENGH ${ }^{3}$

Morsoletto EM, Amarante HMS, Ardengh JC. Inappropriate decontamination of gastrointestinal endoscope and acessories. Is this the Brazilian reality? Arq Gastroenterol. 2006;43(4):253-4.

HEADINGS - Equipment contamination. Disinfection. Endoscopes.

\section{REFERÊNCIAS BIBLIOGRÁFICAS}

1. Amarante HMBS, Leitão OR. Limpeza e desinfecção dos endoscópios. In: SOBED Sociedade Brasileira de Endoscopia Digestiva, editor. Endoscopia digestiva diagnóstica e terapêutica. Rio de Janeiro: Revinter; 2004. p. 37-43.

2. Costa ML, Cardo DM, Ferrari AP. Levantamento de rotinas de reprocessamento de endoscópios em hospitais do Município de São Paulo. GED Gastroenterol Endosc Dig. 1997;16:41-6.

3. Fireman Z. Biopsy forceps: reusable or disposable? J Gastroenterol Hepatol 2006;21:1089-92.Lubowski DZ, Newstead GL. Rigid sigmoidoscopy: a potential hazard for cross-contamination. Surg Endosc 2006;20:812-4.

4. Lubowski DZ, Newstead GL. Rigid sigmoidoscopy: a potential hazard for crosscontamination. Surg Endosc. 2006;20:812-4.

5. Machado AP, Pimenta ATM, Gontijo PP, Geocze S, Fischman O. Microbiologic profile of flexible endoscope disinfection in two Brazilian hospitals. Arq Gastroenterol 2006;43:255-8.
6. Morris J, Duckworth GJ, Ridgway GL. Gastrointestinal endoscopy decontamination failure and the risk of transmission of blood-borne viruses: a review. J Hosp Infect. 2006;63:1-13.

7. SGNA Practice Committee. Reprocessing of endoscopic accessories and valves. Gastroenterol Nurs 2006;29:394-5.

8. SGNA Practice Committee. Reprocessing of water bottles used during endoscopy. Gastroenterol Nurs 2006;29:396-7.

9. SOBEEG SBdEeEG. Manual de reprocessamento de limpeza e desinfecção de aparelhos e acessórios endoscópicos. Salvador: P\&A Gráfica; 2000.

10. Vanhems P, Gayet-Ageron A, Ponchon T, Bernet C, Chayvialle JA, Chemorin C, Morandat L, Bibollet MA, Chevallier P, Ritter J, Fabry J. Follow-up and management of patients exposed to a flawed automated endoscope washer-disinfector in a digestive diseases unit. Infect Control Hosp Epidemiol. 2006;27:89-92.

11. WGO-OMGE/OMED Practice GuidelineS. Endoscope desinfection. [monograph on the Internet]. Munich, Germany: WGO; 2005. [cited 2007 Jan 15]. Available from http://www.omgw.org/globalguidelines/guide 14/guideline 14.htm.

${ }^{1}$ Faculdade Evangélica de Medicina do Paraná, Curitiba, PR.; ${ }^{2}$ Faculdade de Medicina da Universidade Feral do Paraná, Curitiba, PR.;

${ }^{3}$ Hospital das Clínicas da Faculdade de Medicina de Ribeirão Preto da Universidade de São Paulo, Ribeirão Preto, SP. 